\title{
Surface Subsidence Induced by Groundwater Drainage Tunneling in Granite Residual Soils (Burata Railway Tunnel, Spain)
}

\author{
Carlos López-Fernández; Daniel Arias Prieto²; Gabriela Fernández-Viejo ${ }^{3}$; Luis Alberto Pando González"; \\ and Enrique Castells Fernández ${ }^{5}$
}

\begin{abstract}
Underground tunneling, besides raising geotechnical challenges, can often modify the hydrological regime around an excavated area. This fact entails not only the modification of superficial aquifers but also the appearance of subsidence phenomena as a consequence of the decrease in pore pressure. In the end, this may jeopardize the structural integrity of the construction, leading to delays and undesirable secondary effects. This paper documents the problems arising from the construction of a railway tunnel for a high-speed train in the province of Orense in the northwest of Spain. The tunnel was excavated through a highly weathered granitic massif using conventional methods. The drawdown in the water table caused by the tunnel advance was analyzed and monitored. The initial lowering of the water level was followed by a period of soil subsidence with deflections reaching up to $104 \mathrm{~mm}$. These differential settlements happened along a 150-m strip on both sides of the tunnel axes, which affected urbanized areas. The topographic downfall was located ahead of the perforation head; however, it occurred after the lowering of the water table as an immediate consequence. DOI: 10.1061/(ASCE)GT.1943-5606.0000805. () 2013 American Society of Civil Engineers.
\end{abstract}

CE Database subject headings: Groundwater; Drainage; Residual soils; Land subsidence; Settlement; Tunnels; Spain.

Author keywords: Groundwater drainage; Granite residual soils; Subsidence; settlements; Tunnel.

\section{Introduction}

The excavation of the Burata tunnel in the northwest of Spain below the groundwater level through a strongly weathered granite massif induced the drawdown of the water table to the excavation level. The superficial aquifers emptied along a 150-m strip of land on both sides of the tunnel lineation, reducing the water supply in the surrounding towns. The ground also suffered settlements of up to $104 \mathrm{~mm}$ in the same area prior to the advance of the tunneling works. This is attributed to consolidation of the weathered layers of the granite when the water table drops. There are abundant references related to this problem, both in the field of tunneling (Lee et al. 2009; Sinclair and Norfolk 2001; Shin and Potts 1998, 2001; Yoo et al. 2007, 2008) and in the overexploitation of aquifers (Zhang et al. 2007; Feng et al. 2008; Tomás et al. 2010). However, there is scarce literature on the

${ }^{1}$ Ph.D., Lecturer, Dept. of Geology, Univ. of Oviedo, Jesús Arias de Velasco, 33005 Oviedo, Spain (corresponding author). E-mail: lopezcarlos@ uniovi.es

${ }^{2} \mathrm{Ph} . \mathrm{D}$., Lecturer, Dept. of Geology, Univ. of Oviedo, Jesús Arias de Velasco, 33005 Oviedo, Spain. E-mail: darias@geol.uniovi.es

${ }^{3}$ Ph.D., Lecturer, Dept. of Geology, Univ. of Oviedo, Jesús Arias de Velasco, 33005 Oviedo, Spain. E-mail: gaby@geol.uniovi.es

${ }^{4}$ Assistant Professor, Dept. of Geology, Univ. of Oviedo, Jesús Arias de Velasco, 33005 Oviedo, Spain. E-mail: pandoluis@uniovi.es

${ }^{5}$ Director of Tunneling, Corsán-Corviam Company (Isolux Corsán Group), Caballero Andante 8, 28021 Madrid, Spain. E-mail: ecastells@ isoluxcorsan.com

Note. This manuscript was submitted on February 24, 2011; approved on July 30, 2012; published online on August 4, 2012. Discussion period open until October 1, 2013; separate discussions must be submitted for individual papers. This technical note is part of the Journal of Geotechnical and Geoenvironmental Engineering, Vol. 139, No. 5, May 1, 2013. @ASCE, ISSN 1090-0241/2013/5-1-4/\$25.00. evaluation of the problem in weathered granites (Shin and Lee 2001; Forth 2004; Shin et al. 2005). The Burata tunnel is part of a highspeed railway line in Spain between Madrid and Santiago [Fig. 1(a)]. It consists of a pilot tunnel and a 3,998m-long main tunnel with 13and $90-\mathrm{m}^{2}$ cross sections, respectively. The tunnel was planned for an average depth of $93 \mathrm{~m}$ [Fig. 1(b)], with a maximum overburden of $141 \mathrm{~m}$, and was excavated from two excavation shafts following the new Austrian tunneling method (NATM) between June 2006 and May 2010. The pilot tunnel advanced ahead of the main excavation by an average of $180 \mathrm{~m}$. Support was implemented through bolts, shotcrete reinforced with steel ribs, and micropilot umbrellas in the tunnel portal and in areas with special problems.

\section{Geological and Geotechnical Studies}

The tunnel runs beneath an area where granites outcrop on the surface. Among the granites there is an abundance of metasediments, veins, and quartz dikes. On top of the granite substrate, an important alteration developed with a dissimilar grade of evolution at depths that reach several tens of meters, reaching a maximum in the topographic lows [Fig. 1(b)]. The preparatory geotechnical study for the Burata tunnel project consisted of a prospection of the land that included a detailed geological mapping at a scale of 1:2,000, the description of 31 geomechanical stations, and the drilling of 27 boreholes [Figs. 1(a) and (b)]. In addition, a geochemical, petrographic, and mineralogical study was also performed on 30 samples taken from the boreholes. Thin-section samples were prepared and analyzed with an electron probe. The results led to the definition of the following three geological units [Fig. 1(b)]: (1) fresh granite (FG), consisting of peraluminum granite of two unweathered micas of medium-to-fine grain; (2) metasediment (MS), consisting of mica schist, quartz schist, and paragneiss; and (3) granite residual (GR) 

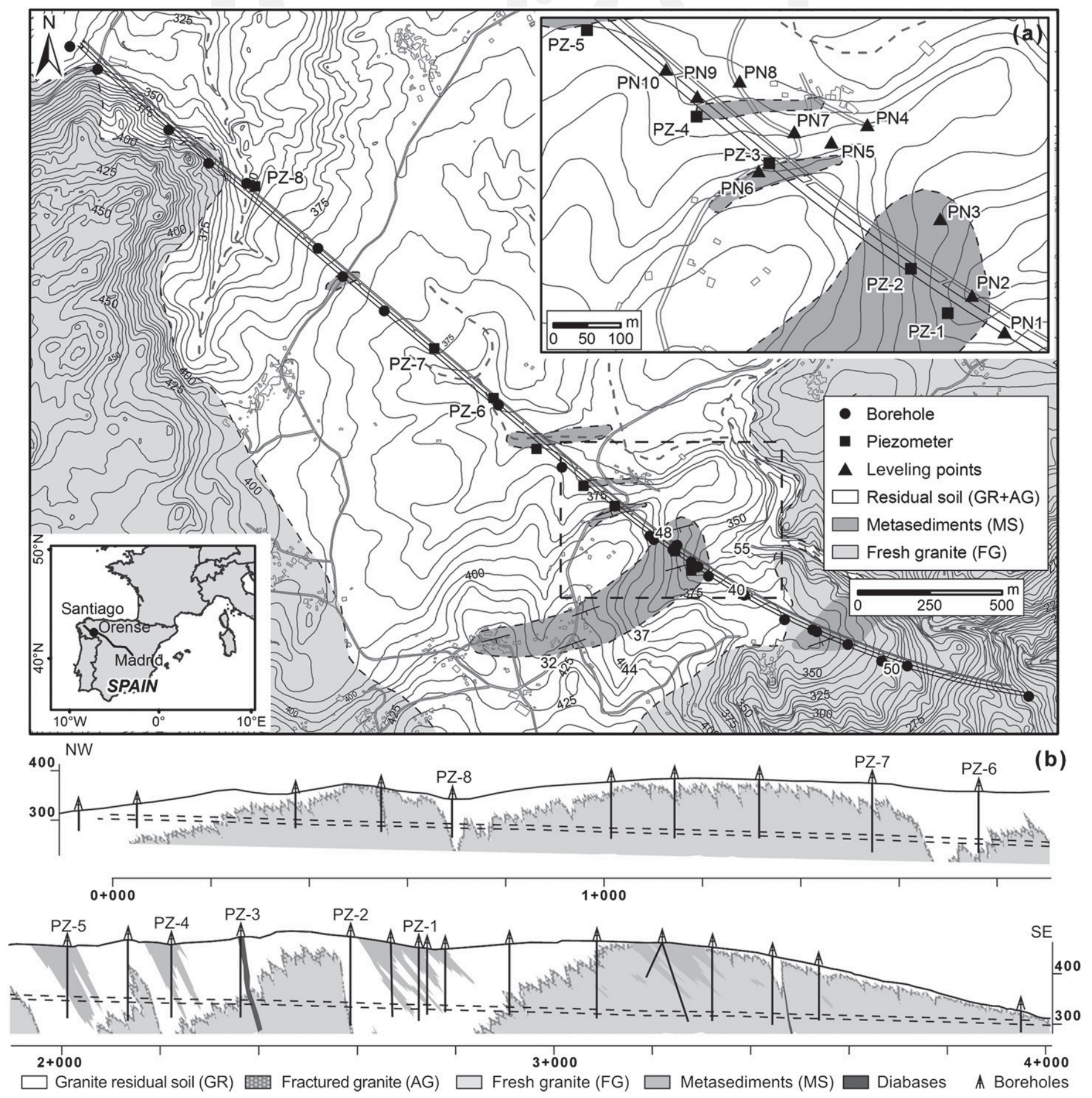

Fig. 1. (a) Geographic location and geological map of the Burata tunnel (also shown are the locations of the drill holes, leveling points, and piezometers; the upper inset is shown as an enlargement of the central part of the tunneling trace) and (b) Geological cross section along the trace of the Burata tunnel

soil generated by the destruction of certain minerals as a consequence of oxidation and hydration processes derived from the groundwater action.

\section{Groundwater Evolution}

The granite residual soil behaves as an unconfined aquifer delimited by unweathered bedrock acting as an impermeable layer. Its hydrological behavior is determined by the grain-size distribution, with the variable content of clays and sands affecting the permeability (generally, between $10^{-3} \mathrm{~m} /$ day for the more clayed facies and $1 \mathrm{~m} /$ day for the coarse sands, estimated by the Lefranc test). During the excavation the hydrological behavior of the massif was measured by eight piezometers situated along the tunnel alignment [Fig. 1(a)], together with the monitoring of more than 200 shallow wells. In five of the piezometers (PZ-1-PZ-5) a lowering of the water table was observed (Fig. 2), in which the lowering reached 


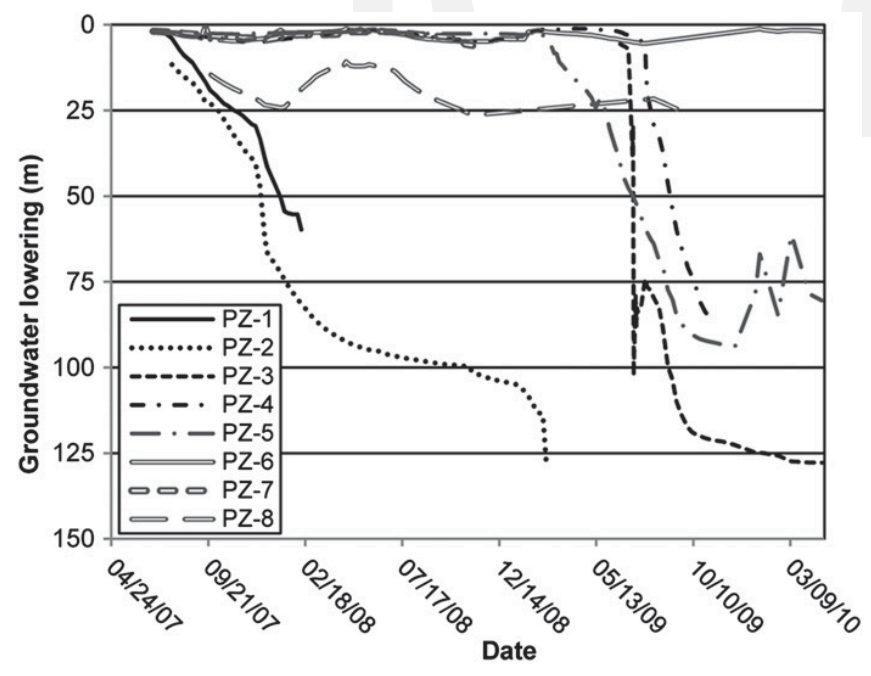

Fig. 2. Evolution of the water table observed in the piezometers during the tunnel work from April 2007 to April 2010

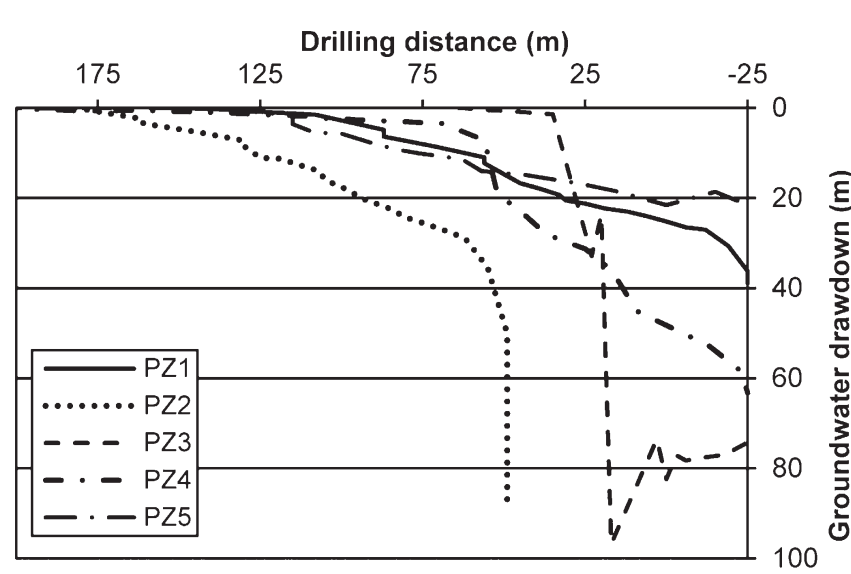

Fig. 3. Drawdown of the water table related to the distance of the perforation head for each of the piezometers the tunnel level. The drawdown was produced at a velocity that ranged between 0.2 and $1 \mathrm{~m} /$ day, with the drawdown always starting before the tunnel excavation reached the piezometer, and with a distance to the pilot tunnel advancing the face between 70 and $175 \mathrm{~m}$ (Fig. 3). In contrast to this, PZ-6-PZ-8 showed less significant lowering of the water table (Fig. 2) because of their situation inside the fresh granite.

\section{Subsidence Analysis}

The analysis of the subsidence associated with the excavation was performed through topographic leveling, with 10 control points located in the zone of the tunnel outline [Fig. 1(a)]. The measurements (with a maximum error estimated at $10 \mathrm{~mm}$ ) were performed weekly from 2007 to 2010 . In all of the measuring points settlements were observed, with ground subsidence ranging between 32 and $104 \mathrm{~mm}$ (Fig. 4). An estimate of the subsidence rate oscillated between 0.2 and $0.9 \mathrm{~mm} /$ day. The observed subsidence affected a part of the terrain at least $150-\mathrm{m}$ north of the tunnel. The settlements started after the lowering of the water table.

\section{Discussion and Conclusions}

From the data recorded throughout the excavation of the tunnel, it can be deduced that the surface subsidence observed around the Burata tunnel was mainly caused by the generalized drawdown in the water table as a result of tunnel drainage, with the excavation process being a negligible factor in the final topographic drop. The advance of the tunneling work through the most weathered parts of the granite massif caused the water to flow toward the excavation, affecting an area of 70-175 m ahead of the pilot tunnel advancing face. This range of distances is a direct consequence of the various degrees of permeability in the granite residual soils (which are grainsize dependent). Moreover, the fall in the level of the water table led to consolidation of the soil. This fact is reflected in the appearance of the settlements in the topographic profile, whose magnitude reached up to $104 \mathrm{~mm}$. These settlements are proportional to the relative thickness of the weathered layer of the granite affected by the water table variation and have been estimated to be $0.8 \mathrm{~mm} / \mathrm{m}$.
77

78

79

80

81

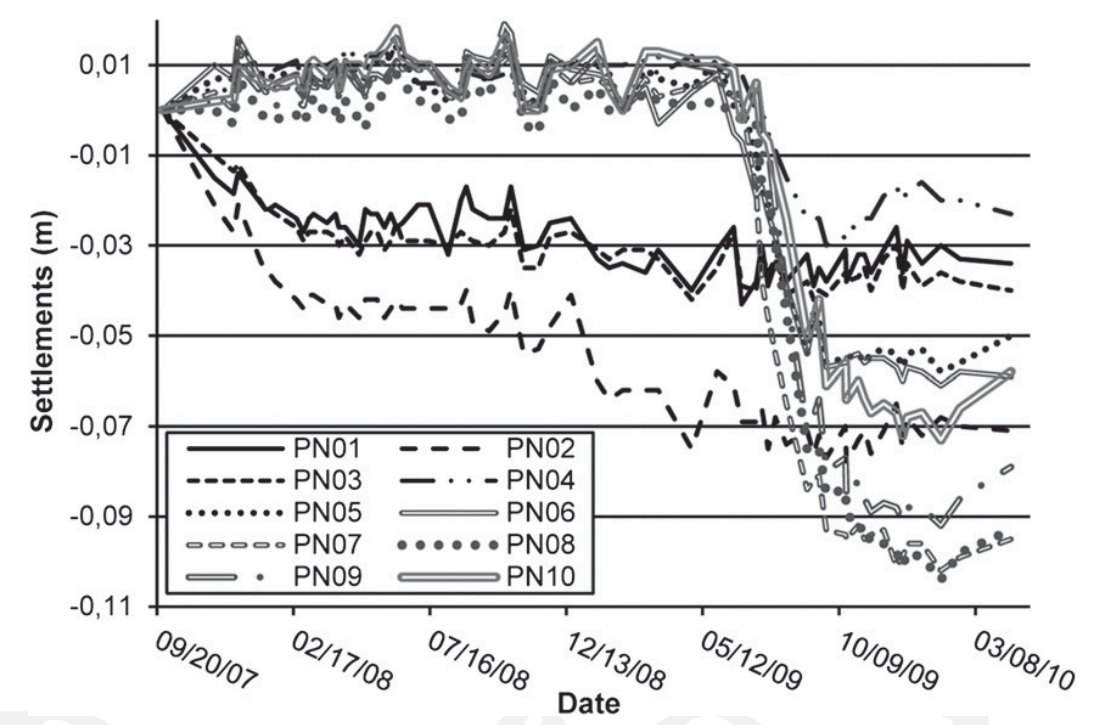

Fig. 4. Settlements measured in the leveling points [their location is shown in Fig. 1(a)] 


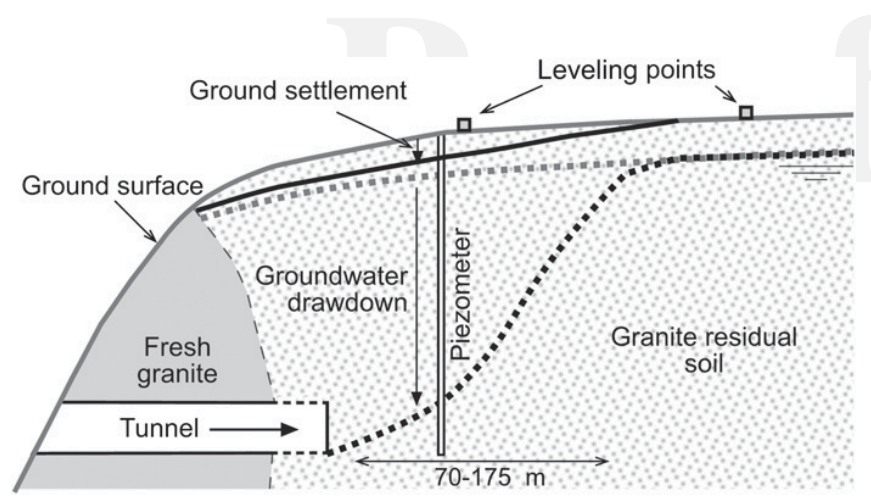

Fig. 5. Model of the subsidence processes caused by the water table drawdown
This case has been the first one to be monitored in Spain (where there are more than $1,500 \mathrm{~km}$ of railway and road tunneling), and is comparable to the Seoul Underground, where settlement values reached $160 \mathrm{~mm}$, with a drawdown in the water table of $16 \mathrm{~m}$ for a typical thickness cover of 15-40 m (Yoo et al. 2008). The values obtained for the settlements induced here can be compared with those related to the overexploitation of aquifers. One example is the city of Murcia, Spain, where average settlements of $76 \mathrm{~mm}$ were caused by the generalized lowering of the water table by $25 \mathrm{~m}$ (Tomás et al. 2010), or the case of Changzhou, China, with settlements of $600 \mathrm{~mm}$ related to a water drawdown of $20 \mathrm{~m}$ (Wang et al. 2009).

In conclusion, subsidence processes related to lowering of the water table can be expected in all excavations occurring in weathered rock massifs or in permeable soils where water flow runs into the excavation (Fig. 5). The water drawdown implies a reduced pore pressure that is translated toward the surface, inducing various settlement problems. These settlements are also instantaneous when there is not a large amount of clay, as is this here. The quantification and prediction of the subsidence phenomena depend on several variables; i.e., the weathering grade of the massif, the thickness of the residual soil, the magnitude of the drop in the water table level, the excavation method, and the distance to the excavation advancing face.

\section{Acknowledgments}

This work has been financed by Project CTM2009-11522 of the Ministry of Science and Technology of Spain. Comments and suggestions by Jesper Fallesen improved the quality of the paper. The authors thank Robin Walker of englishglobal.com for revision of the English grammar and structure.

\section{References}

Feng, Q.-Y., Liu, G.-L., Meng, L., Fu, E.-J., Zhang, H.-R., and Zhang, K.-F. (2008). "Land subsidence induced by groundwater extraction and building damage level assessment-A case study of Datun, China." J. China Univ. Min. Technol.., 18(4), 556-560.

Forth, R. A. (2004). "Groundwater and geotechnical aspects of deep excavations in Hong Kong." Eng. Geol., 72(3-4), 253-260.

Lee, Y. J., Kim, S. B., and Yoo, C. (2009). "Characteristics of tunnelinginduced ground settlement in groundwater drawdown environment." Proc., 6th Int. Symp on Geotechnical Aspects of Underground Construction in Soft Ground, C. W. W. Ng, H.W. Huang, and G. B. Liu, eds. Shanghai, 485-490.

Shin, J. H., and Lee, I. K. (2001). "A study on the failure mechanism of the mixed-face tunnels in decomposed granite." J. Korea Geotech. Soc., 14(4), 317-329.

Shin, J. H., and Potts, D. M. (1998). "Settlements above tunnels constructed in weathered granite." Tunnels and metropolises, Negro and Ferreira, eds., Balkema, Rotterdam, Netherlands, 375-380.

Shin, J. H., and Potts, D. M. (2001). "Constitutive models for decomposed Granite soil and their application to tunnelling problems." J. Korea Geotech. Soc., 17(1), 131-139.

Shin, J. H., Potts, D. M., and Zdravkovic, L. (2005). "The effect of porewater pressure on NATM tunnel linings in decomposed granite soil.' Can. Geotech. J., 42(6), 1585-1599.

Sinclair, T. J. E., and Norfolk, P. D. (2001). "Settlements over closeproximity tunnels in saturated sands: Prediction and performance." Proc., Geotechnical Engineering Meeting on Society's Needs, K. K. S. Ho and K. S. Li, eds., 431-436.

Tomás, R., Herrera, G., Delgado, J., Lopez-Sanchez, J. M., Mallorquí, J. J., and Mulas, J. (2010). "A ground subsidence study based on DInSAR data: Calibration of soil parameters and subsidence prediction in Murcia City (Spain)." Eng. Geol., 111(1-4), 19-30.

Wang, G. Y., You, G., Shi, B., Yu, J., and Tuck, M. (2009). "Long-term land subsidence and strata compression in Changzhou, China." Eng. Geol., 104(1-2), 109-118.

Yoo, C., Kim, S.B., Lee, J.T., (2007). "Tunnel construction risk assessment for Seoul Metro Subway Contract 9-15 Tunnel Design Project.” Rep., Hyundai Engineering and Construction, Seoul, Korea.

Yoo, C., Kim, S. B., Kim, J. W., and You, K. H. (2008). "Influencing factors on groundwater drawdown induced ground settlement during tunnelling." Proc., World Tunnelling Congress, 863-871.

Zhang, Y., et al. (2007). "Characteristics of aquifer system deformation in the Southern Yangtze Delta, China." Eng. Geol., 90(3-4), $160-173$. 